\title{
The nature of limestone filler and self-consolidating feasibility-Relationships between physical, chemical and mineralogical properties of fillers and the flow at different states, from powder to cement-based suspension
}

\author{
Paco Diederich ${ }^{\mathrm{a}, \mathrm{b}, *}$, Michel Mouret ${ }^{\mathrm{a}}$, Alain de Ryck ${ }^{\mathrm{c}}$, François Ponchon ${ }^{\mathrm{b}}$, Gilles Escadeillas ${ }^{\mathrm{a}}$ \\ a Université de Toulouse, UPS, INSA, LMDC (Laboratoire Matériaux et Durabilité des Constructions), 135, avenue de Rangueil, F-31077 Toulouse Cedex 04, France \\ ${ }^{\mathrm{b}}$ Carmeuse France, 91 Avenue d'Acqueville, F-78670 Villennes-Sur-Seine, France \\ c Université de Toulouse, Mines Albi, CNRS, Centre RAPSODEE, Campus Jarlard, F-81013 Albi cedex 09, France
}

\begin{abstract}
A B S T R A C T
This paper is a part of a large study aimed at identifying the physical and chemical properties of limestone fillers (LF) that govern their behaviour towards self-consolidating flow. Five LF were studied, complying with the standards and selected for their significant differences in properties on the basis of the supplier's database. Despite their specific manufacturing, a thorough characterization showed that the selected LFs had very different properties in terms of surface charges, morphology, wettability and size distribution. Then, relationships were sought between these properties and the flow of LF in powder form and suspended in water, or water + polycarboxylate type High Range Water Reducer Admixture (HRWRA), or water + HRWRA + cement (OPC or slag blended cement). The flow measurements concerned flowability, floodability and shear under consolidation in the dry state, and static yield stress and apparent viscosity in the suspension state. The main results show that the LFs act in the same way on the flow as long as cement is not incorporated into the suspension. From the dry state to the water + HRWRA suspensions, the flow is dependent on the fineness of the LF. The significant relationships between the surface charges, wettability and fineness of LFs show that impurities like clays are key factors in the flow of LF suspensions. When cement was incorporated into the suspension, the flow was dependent on the interactions existing among all the constituents. Then, with a view to self-consolidating applications, it becomes possible to identify how best to incorporate LF in a cement-based matrix through the measurement of the arrangement of cement and filler particles in suspension.
\end{abstract}

Keywords:

Powder flow

Tribo-electrification

Shear of powder

Rheological test

Kendall's coefficients

Wet packing density

\section{Introduction}

Developed in the 80s in Japan, self-consolidating concrete (SCC) is designed to be put in place without any outside energy (vibration). To achieve the required properties in the fresh state, i.e. compaction by gravity alone without excessive bleeding and segregation problems, it was necessary to modify the mix design of traditional vibrated concrete. In practice, self-consolidating ability is obtained by a higher proportion of cementitious materials (cement and mineral admixtures). The greater quantity of paste limits friction between coarse aggregates and promotes the flow of the concrete [1].

Generally designed with $500 \mathrm{~kg}$ and possibly up to $625 \mathrm{~kg}$ of cementitious materials per $\mathrm{m}^{3}$ of concrete [2], a significant replacement level of cement is used to lower the cost, the hydration heat and the

\footnotetext{
* Corresponding author at: Université de Toulouse, UPS, INSA, LMDC (Laboratoire Matériaux et Durabilité des Constructions), 135, avenue de Rangueil, F-31077 Toulouse Cedex 04, France.

E-mail address: paco.diederich@gmail.com (P. Diederich).
}

environmental impact (savings in energy consumption and $\mathrm{CO}_{2}$ release into the atmosphere).

Accordingly, self-consolidating concrete designs incorporate various mineral additions like fly-ash and different types of stone dusts. In France, because of its low price and wide availability, limestone powder is being increasingly used.

For some exposure classes of concrete structure, the specifications of European standard EN 206-1 [3] show that the maximum mass of limestone filler in a concrete design can reach $33 \%$ of the mass of the cement $($ filler/filler + cement $=0.25)$. Although pre-dating the publication of standard EN 206-1, many SCC designs reported in the literature include more than this limit quantity (43\% for [4], up to $65 \%$ for [5] and [6]). In these works, both pioneering and normative, it appears that the quantity of such a mineral admixture is significant in SCC designs. Accordingly, the impact of the properties of limestone filler on the design of SCC and the resulting properties in both the fresh and hardened states cannot be ignored. In field applications, it is reported that a change in the nature of the limestone filler, still complying with the French standard requirements [7], can induce unexpected issues like segregation or poor external aspect for a 
given SCC mix. Hence, it is worthwhile to understand why some fillers are not usable in a given SCC design, whose feature lies in the fresh state.

Although some properties of limestone filler (LF) that influence the flow of cement-based materials have already been highlighted in the literature (fineness, particle size distribution, nature and amount of impurities), the findings of the various works often disagree, depending on the techniques used to characterize the properties. The discrepancy is particularly marked with regard to fineness. Some studies show that a greater fineness, characterized by the BET specific surface area, is related to a higher water demand of cement pastes, mortars [8] and concrete [9,10]. Accordingly, yield stress and viscosity are increased at given water content in concrete [10]. Conversely, a higher fineness, characterized by the Blaine specific surface area, and combined with a wide particle size distribution (high uniformity coefficient) leads to a decrease in the water demand of cement pastes [11].

In addition, the presence of impurities, such as clay, increases the water demand [8]. In the same way, an increase in the $\mathrm{MgO}$ content increases the viscosity by interacting with the High Range Water Reducer Admixture (HWRA or superplasticizer) [12].

This paper is part of a large study [13] dealing with the identification of the physical and chemical properties of limestone fillers (LF) which govern their behaviour towards self-consolidating flow. The methodology can be divided into several steps, from the characterization of LF in the dry state (powder) to the characterization of LF in suspension (from aqueous suspensions to concrete suspensions). Here, in the case of five LF selected because they present significant differences in their properties on the basis of the supplier's database, the flow is studied in the first three states, i.e. powder, LF suspended in water or water + HRWRA, and cement-based suspensions at the paste scale. A systematic analysis of relationships is made between $\mathrm{i}$ ) properties of LF and flow properties, ii) flow properties in the different states. Thus, it becomes possible to identify how best to incorporate LF in a cement-based matrix in view of self-consolidating applications.

\section{Raw materials}

The cements used were a CEM I 52.5 N CE CP2 NF and a CEM III/A 52.5 L CE CP1 NF complying with European standard EN 197-1 [14]. The High Range Water Reducer Admixture was a polycarboxylate type commercially available as a solution (specific gravity $=1.05 \mathrm{~kg} / \mathrm{m}^{3}$; active solid content per mass $=21.6 \%$ ).

Five fillers were selected from sites among those producing limestone powders in accordance with the French standards for mineral additions in concrete [7]. The selection was made by considering the significant differences in the physical and chemical properties of the powders, provided by the quality control database of the supplier. The differences between properties (Blaine specific surface area, laser diffraction median diameter $\mathrm{d}_{50}$, clay content, chemical composition) were assessed by means of a principal component analysis (PCA) and a hierarchical ascendant classification on the data derived from PCA.

\subsection{Main properties}

The main physical and chemical properties of the powders (cements and limestone fillers) are gathered together in Table 1. The size distribution of the powders is shown in Fig. 1. It is important to note that LF1, LF2 and LF4 fillers exhibit a bimodal distribution while LF3 and, to some extent, LF5 fillers have a monomodal distribution. These differences are explained by the hardness of the stone and by the grinding procedure. For bimodal distributions, the sizes of the finest and coarsest particles are limited by the crystal size of the rock and the grinding process respectively. In the case of a monomodal distribution, bigger crystal sizes associated with the grinding process imply that the size classes are merged into one.
Table 1

Main properties of powders.

\begin{tabular}{|c|c|c|c|c|c|c|c|}
\hline & LF1 & LF2 & LF3 & LF4 & LF5 & CEM I & CEM III \\
\hline $\mathrm{CaO}(\%)$ & 54.55 & 54.83 & 54.55 & 55.39 & 54.05 & 65.40 & 55.70 \\
\hline $\mathrm{SiO}_{2}(\%)$ & 0.71 & 0.50 & 0.10 & 0.09 & 1.55 & 20.43 & 26.10 \\
\hline MgO (\%) & 0.38 & 0.33 & 0.86 & 0.18 & 0.32 & 1.06 & 3.45 \\
\hline $\mathrm{Fe}_{2} \mathrm{O}_{3}(\%)$ & 0.37 & 0.26 & 0.11 & 0.05 & 0.27 & 1.83 & 1.20 \\
\hline $\mathrm{Al}_{2} \mathrm{O}_{3}(\%)$ & 0.17 & 0.12 & 0.03 & 0.03 & 0.37 & 4.90 & 7.40 \\
\hline $\mathrm{K}_{2} \mathrm{O}(\%)$ & 0.04 & 0.02 & 0.004 & 0.004 & 0.09 & 0.27 & 0.34 \\
\hline $\mathrm{Na}_{2} \mathrm{O}(\%)$ & 0.02 & 0.02 & 0.03 & 0.02 & 0.03 & 0.19 & 0.38 \\
\hline $\mathrm{SO}_{3}$ & - & - & - & - & - & 3.60 & 2.64 \\
\hline Calcite $\mathrm{CaCO}_{3}(\%)$ & 97.6 & 98.1 & 97.6 & 99.1 & 96.7 & - & - \\
\hline $\begin{array}{l}\text { Dolomite CaMg } \\
\left(\mathrm{CO}_{3}\right)_{2}\end{array}$ & $\varnothing$ & $\varnothing$ & $\mathrm{X}$ & $\varnothing$ & $\varnothing$ & - & - \\
\hline Quartz $\mathrm{SiO}_{2}$ & $\varnothing$ & $\varnothing$ & $\varnothing$ & $\varnothing$ & $\mathrm{X}$ & - & - \\
\hline $\begin{array}{l}\text { Methylene blue } \\
\text { adsorption } \\
\text { (g/kg filler), (clay } \\
\text { content) [15] }\end{array}$ & 2.66 & 1.33 & 0.66 & 0.66 & 1.33 & - & - \\
\hline $\begin{array}{l}\text { Solid specific gravity } \\
\qquad\left(\mathrm{kg} / \mathrm{m}^{3}\right) \\
\text { (by pycnometer) }\end{array}$ & 2720 & 2710 & 2710 & 2700 & 2710 & 3110 & 3010 \\
\hline $\begin{array}{l}\text { Blaine specific } \\
\text { surface area } \\
\left(\mathrm{cm}^{2} / \mathrm{g}\right)( \pm 500)\end{array}$ & 6530 & 4650 & 3910 & 4990 & 4050 & 3750 & 3760 \\
\hline $\begin{array}{l}\text { Nitrogen BET } \\
\text { specific surface } \\
\text { area }\left(\mathrm{cm}^{2} / \mathrm{g}\right) \\
( \pm 600)\end{array}$ & 26,400 & 16,500 & 10,800 & 11,100 & 15,000 & 12,500 & 12,900 \\
\hline
\end{tabular}

detected by X-ray diffraction.

${ }^{\varnothing}$ Not detected.

Based on the uniformity coefficient (Fig. 1) [16], LF2 and LF5 powders are defined as well graded while the other three (LF1, LF3, LF4) can be considered as non-uniform.

Also, it can be noted that the fillers are classified in the same order if properties such as the \% passing a $5 \mu \mathrm{m}$ sieve (Fig. 1 ) and the Blaine specific surface area (Table 1) are used. In addition, even though the fineness of the LF4 filler is clear from Fig. 1, the corresponding BET surface is quite low (Table 1). As already noted elsewhere [8], this specificity may be related to the lower clay content of this powder (Table 1).

\subsection{Specific properties of limestone fillers}

With a view to understanding why certain fillers have different self-consolidating abilities, some factors influencing their flow
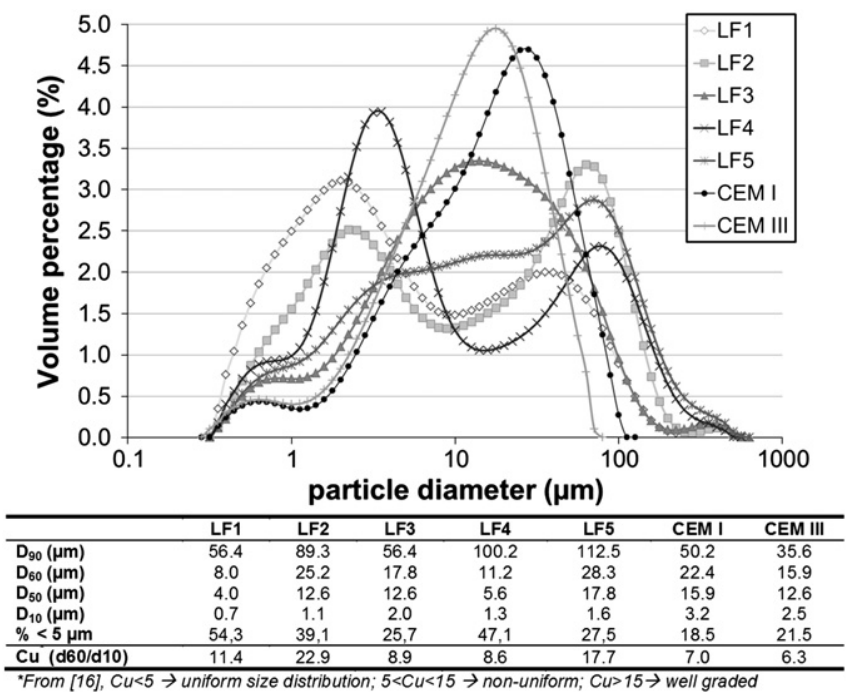

Fig. 1. Powder particle size distribution (laser diffraction by wet sample dispersion mode). 
behaviour in the dry state and in suspension were investigated, i.e. morphology, surface charge and affinity with liquid phase.

\subsubsection{Morphology}

The shape of fillers was obtained by means of an optical microscope equipped with an automated particle characterization system. The dispersion of grains was made possible by an instantaneous pulse of compressed air at a pressure of 4 bars so as to achieve a homogeneous dispersion and avoid touching particles.

For each particle counted (30,000 grains analysed for a given filler), a two-dimensional (2D) image was captured at 20× magnification so that size and various shape parameters could be calculated for particles larger than or equal to $1 \mu \mathrm{m}$. Particles finer than $1 \mu \mathrm{m}$ were not studied because of a lack of resolution. A hole filling method was applied on each image for accurate estimation of the length and width of particles. The size was evaluated as the diameter of a circle with the same area as the 2D image of the particle. A previous study has shown that at least elongation and ruggedness are required to characterize the attributes of shape [17]. Elongation was characterized by the aspect ratio (particle width taken perpendicular to the length divided by the particle length, defined as the longest dimension of the particle) while the boundary irregularity of a particle was quantified by the form factor (square of the ratio between the circumference of the circle of equivalent area and the actual perimeter of the grain). A value close to 1 for aspect ratio and form factor corresponds to a round, smooth particle.

The mean values per size class of aspect ratio and form factor are plotted in Fig. 2 together with the 95\% confidence intervals for the mean values. Since the shape descriptors were found not to be normally distributed, the confidence intervals were determined by means of the bootstrap technique [18].

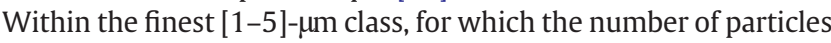
was the highest, LF3 filler had the most elongated and irregular grains. Even though similar values of the aspect ratio were observed for the other fillers, more irregular grains existed for LF1 and LF4 than for LF2 and LF5 (Fig. 2b).
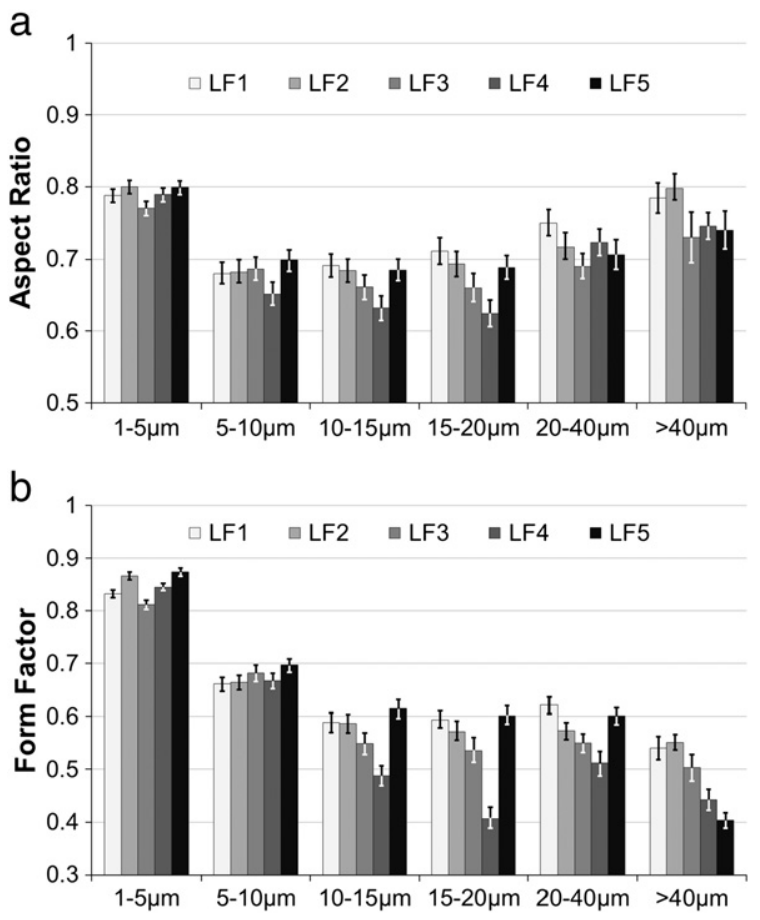

Fig. 2. Aspect ratio (a) and form factor (b) of the limestone fillers.
Within [5-20] $\mu \mathrm{m}$ classes, the aspect ratio was smaller for LF4 than for the other fillers (Fig. 2a). Significantly lower values of form factor were also found for LF4 from [20-40] $\mu \mathrm{m}$ classes.

In the coarsest class ( $\geq 40 \mu \mathrm{m}$ ), LF3, LF4 and LF5 presented similar but smaller aspect ratio values; the elongated aspect of LF4 and LF5 was associated with a pronounced surface ruggedness since the form factor values of LF4 and LF5 were small in comparison with those of the other fillers.

\subsubsection{Surface charges}

2.2.2.1. Electro-static charges. The tribo-electrification test measures the electrostatic charges existing in a sample of powder placed in a rotating $(92 \mathrm{rpm})$ stainless steel cylinder at controlled temperature $\left(21^{\circ} \mathrm{C}\right)$ and relative humidity $(20 \%)$. The electrostatic charges of the sample are measured in a Faraday cage via an electrometer. The results are presented as a charge per unit mass of powder.

The test showed the existence of very different electrostatic charges, depending on the nature (mineralogical composition and impurities, Table 1 ) of the powders, both at the initial stage $t=0$ (due to handling) and the end of the test, $t=10 \mathrm{~min}$ (Fig. 3). Powders LF1 and LF2 had their initial negative charges increased during the test, particularly powder LF1, which is finer than LF2. In contrast, the powder LF3 had strong positive charges throughout the test. Finally, powders LF4 and LF5 were slightly charged, negatively for LF4, positively for LF5.

2.2.2.2. Zeta potential. In order to verify whether the existing charges on powder grains (Section 2.2.2.1) were maintained in suspension, zeta potentials were measured on dilute suspensions (volume solid concentration value of $1 \%$ ) by means of the laser Doppler electrophoresis technique coupled with phase analysis light scattering. The evolution of the zeta potential in presence of HRWRA (1.0 wt. \% of solids) was also assessed.

Zeta potential values $\zeta$ and the corresponding accuracy (5\%) are plotted on Fig. 4. When suspensions in water only are considered, differences in sign and magnitude of $\zeta$ are directly linked to the electrostatic charges existing on the surface of the powder grains (Fig. 3). LF1 and LF2 fillers were the most negatively charged in the dry state and presented significant negative $\zeta$ when suspended in water. In the same way, LF3 filler, positively charged, exhibited a strong trend to positive $\zeta$ values. LF4 and LF5 fillers, slightly charged in the dry state, kept the sign of the electrostatic force (negative for LF4, positive for LF5); in the case of LF4 filler, the negative repulsive force was even significant in suspension.

Hence, it can be concluded that the electric charges of filler measured in the powder state (Section 2.2.2.1) are maintained or accentuated when fillers are suspended in water. The incorporation of a HRWRA strongly modified the zeta potential. In all cases: the HRWRA maintained (LF1), enhanced (LF2, LF4) or conveyed (LF3,

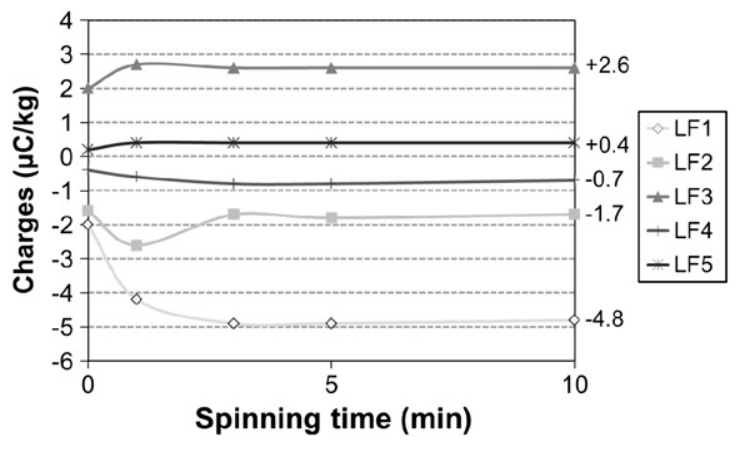

Fig. 3. Electrostatic charges of limestone powders. 


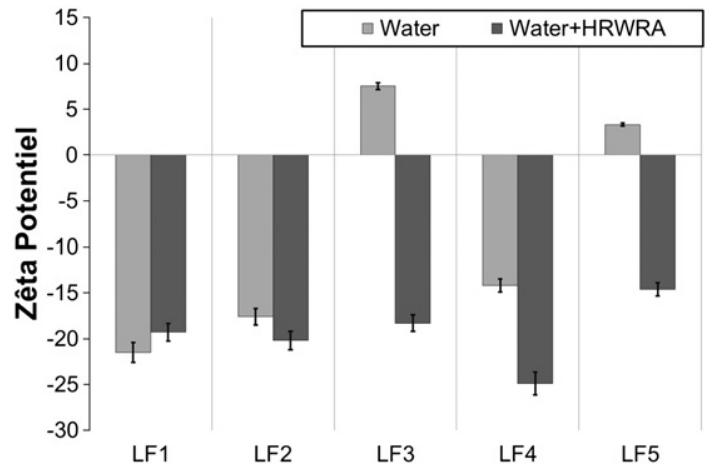

Fig. 4. Zeta potential values of filler in suspension (water or water + HRWRA).

LF5) negative surface charge to the particles. This result indicates that polycarboxylate (PC) molecules act mainly as electrostatic dispersants, like polynaphtalene sulphonate (PNS) molecules. This can be explained by the very dilute suspensions used to measure $\zeta$ and the large HRWRA content (1.0 wt.\% of solids), which resulted in the steric forces not being predominant in the dispersing effect of the PC-type HRWRA. Nevertheless, the sharp decrease in $\zeta$, from positive to negative values, with the increase in the amount of PC-type HRWRA in limestone suspensions has already been observed under different conditions of solid volume concentration and $\mathrm{pH}$ in suspensions [19]. A similar evolution was also noted with limestone suspensions containing a polyacrylic-acid-based dispersant [20].

\subsubsection{Affinity of fillers with liquid phase}

Different surface properties (texture, charges) of the fillers were observed, which undoubtedly imply different energies existing at the surface of the grains. So, it is important to apprehend the interaction between fillers and a liquid phase. The capillary ascension test was used to obtain a comparative indication of the wettability of the fillers studied. In this test, the sample of powder was placed in contact with the aqueous solution and the mass of absorbed liquid in the sample was measured as a function of time. Hence, a contact angle was deduced using the Washburn relation. A preliminary test was run with a totally wetting liquid (Hexane) to determine the experimental conditions which were strongly dependent on the structure of the powder and the characteristics of the measuring cell. Then, the test was performed again with the testing liquid to determine the contact angle. Two different aqueous solutions were used: either pure water or water containing HRWRA ( $0.3 \%$ by mass of powder). The HRWA content was the same as the one used in preliminary tests assessing the sedimentation of filler particles suspended in water + HRWRA.

The tests performed with pure water showed that all powders had high contact angle values (Table 2 ), indicating a rather low hydrophilic behaviour. Conversely, when HRWRA was incorporated in the water, the contact angles evolved differently depending on the nature of the filler. It can be noted that powders LF1 and LF2 showed a decrease in contact angle, i.e. a higher affinity with the aqueous solution (these two powders were also both negatively charged) while LF3, LF4 and LF5 showed a lower affinity with the liquid phase (increase in the contact angle). Hence, it can be concluded that the interaction between the powder and the HRWRA is dependent on the nature of the powder

Table 2

Contact angles of powders.

\begin{tabular}{llllll}
\hline & LF1 & LF2 & LF3 & LF4 & LF5 \\
\hline Pure water $\left({ }^{\circ}\right)$ & $78.7 \pm 0.6$ & $77.6 \pm 0.8$ & $66.4 \pm 1.6$ & $77.0 \pm 1.4$ & $71.4 \pm 0.5$ \\
Water + HRWRA $\left({ }^{\circ}\right)$ & $66.9 \pm 2.6$ & $53.4 \pm 6.4$ & $72.4 \pm 0.7$ & $86.2 \pm 0.4$ & $76.1 \pm 1.5$ \\
\hline
\end{tabular}

and, to some extent, this interaction can influence the rheological properties of suspensions. This fact will be discussed later (Section 4.2).

\section{Experimental programme}

This section presents the experimental procedures for the measurement of flow properties, from dry limestone fillers (LF) to more and more complex suspensions (water $+\mathrm{LF}$, water $+\mathrm{HRWRA}+\mathrm{LF}$, water + HRWRA + cement + LF).

\subsection{Flow of dry limestone powders}

The techniques for measuring the flow of dry powders were derived from powder technology $[21,22]$ and are widely used in the pharmaceutical and paint fields.

\subsubsection{Flowability and floodability}

Powders used as mineral additions for concrete are generally composed of particles less than $125 \mu \mathrm{m}$ in diameter. Due to the small size of their particles and the charges existing between them, limestone fillers are very cohesive and require high flow energy. The flowability and floodability were determined using simple characterization tests and a resulting classification scale developed by Carr [23]. Flowability represents the capability of a powder to flow under a specified set of conditions (pressure, air humidity, etc.). Floodability is the tendency to liquid-like flow due to natural fluidization of a mass of particles by air (ability to dust). The results of eight simple measurements, analysed through a rating, make it possible to calculate the flowability and floodability indexes and, for each index, to obtain the classification of the powder under test. The tests are listed and briefly presented in Table 3. For the sake of

Table 3

Carr indexes-definitions and critical values.

\begin{tabular}{|c|c|}
\hline Simple tests & Carr indexes \\
\hline $\begin{array}{l}\text { Angle of repose ( } 0 \text { to } 25) \\
+ \\
\text { Angle of spatula ( } 0 \text { to } 25 \text { ) } \\
+ \\
\text { Compressibility ( } 0 \text { to } 25 \\
+ \\
\text { Cohesion ( } 0 \text { to } 25)\end{array}$ & $\begin{array}{l}\text { Carr flowability index: } \\
\text { From } 0 \text { to 59: bad flowability } \\
\text { From } 60 \text { to } 89 \text { : good flowability } \\
\text { From } 90 \text { to } 100 \text { : very good flowability } \\
\text { The lower this index, the greater the } \\
\text { difficulty of the powder to be poured out, } \\
\text { with possible arch generation }\end{array}$ \\
\hline $\begin{array}{l}\text { Angle of fall ( } 0 \text { to } 25) \\
+ \\
\text { Angle of difference ( } 0 \text { to } 25) \\
+ \\
\text { Dispersibility ( } 0 \text { to } 25) \\
+ \\
\text { Flowability index ( } 0 \text { to } 25)\end{array}$ & $\begin{array}{l}\text { Carr floodability index: } \\
\text { From } 0 \text { to 24: will not flood } \\
\text { From } 25 \text { to 39: may flood } \\
\text { From } 40 \text { to 59: tends to flood } \\
\text { From } 60 \text { to 79: fairly high } \\
\text { From } 80 \text { to 100: very high } \\
\text { The lower this index, the more unstable } \\
\text { and irregular the flow due to aeration }\end{array}$ \\
\hline Angle of repose: & $\begin{array}{l}\text { The angle of a heap of powder falling } \\
\text { on a cylinder through a vibrating sieve } \\
\text { and a funnel. }\end{array}$ \\
\hline Angle of fall: & $\begin{array}{l}\text { The new angle of the heap measured after } \\
\text { a constant impact force is applied to the } \\
\text { powder forming an angle of repose. }\end{array}$ \\
\hline Angle of difference: & $\begin{array}{l}\text { The difference between the two previous } \\
\text { measurements. }\end{array}$ \\
\hline Angle of spatula: & $\begin{array}{l}\text { The angle obtained by extracting powder } \\
\text { from a sample with a rectangular spatula. }\end{array}$ \\
\hline Compressibility: & $\begin{array}{l}\text { The ratio of the aerated bulk density to the } \\
\text { packed bulk density. }\end{array}$ \\
\hline Cohesion: & $\begin{array}{l}\text { An experimental relation between } \\
\text { the samples passing through various sieves } \\
(150 \mu \mathrm{m}, 75 \mu \mathrm{m} \text { and } 45 \mu \mathrm{m}) \text {. }\end{array}$ \\
\hline Dispersibility: & $\begin{array}{l}\text { Percentage of powder collected in a watch } \\
\text { glass after falling through a tube. }\end{array}$ \\
\hline
\end{tabular}


good repeatability, all the measurements were automated in one apparatus under fixed temperature and relative humidity $\left(20^{\circ} \mathrm{C}\right.$, $35 \% \mathrm{RH})$. Table 3 also gives the definition and the rating of flowability and floodability indexes.

\subsubsection{Shear of dry powders under consolidation}

The flowability is greatly dependent on the consolidation of the powder, resulting from previous handling (compression in a silo for example). The consolidation stress applied to the powder involves a rearrangement of the particles, which are subjected to plastic deformation and may possibly break into finer particles. As a result, there is an increase in the number and surface area of grains and an increase in the bridging strength between particles. Thus, it is important to assess the evolution of the flowability of the fillers according to the consolidation state. To that end, a Schulze ring shear tester [24] was used. For each consolidation state, the following procedure was applied (Fig. 5). The sample was first pre-sheared under a normal stress $\sigma_{\text {pre }}$ until a steady state flow, defined by a constant shear stress $\tau_{\text {pre }}$ (critical consolidation), was achieved. Then, $\sigma_{\text {pre }}$ was released and the sample was sheared under a normal stress $\sigma_{\text {sh } 1}<\sigma_{\text {pre. }}$. As soon as the yield shear point $\tau_{\text {sh } 1}$ was reached, $\sigma_{\text {pre }}$ was applied again up to the steady state flow. The experiment was repeated seven times with increasing normal stresses $\sigma_{\text {shi }}$ defined as $\sigma_{\mathrm{sh} 1}<\sigma_{\mathrm{sh} 2}<\sigma_{\mathrm{sh} 3}<\ldots<\sigma_{\mathrm{sh} 7}<\sigma_{\mathrm{pre}}$. The flow function ffc was calculated for each consolidation state as the ratio between the consolidation stress $\sigma_{1}$ and the unconfined yield strength $\sigma_{\mathrm{c}}$. The value of $\sigma_{1}$ is equal to the major principal stress of the Mohr stress circle, which is tangential to the yield locus $\left(\sigma_{\mathrm{sh}}-\tau_{\mathrm{sh}}\right.$ line for a given consolidation state, see Fig. 5) and intersects at the point of steady state flow $\left(\sigma_{\text {pre }}, \tau_{\text {pre }}\right)$; the value of $\sigma_{\mathrm{c}}$ results from the stress circle, which is tangential to the yield locus and passes through the origin. Here, four consolidation states were used to determine the flow function ffc: $2.5 \mathrm{kPa}, 5 \mathrm{kPa}, 10 \mathrm{kPa}$ and $19 \mathrm{kPa}$.

\subsubsection{Flow of concentrated suspensions}

\subsubsection{Mix design}

3.1.3.1.1. Aqueous suspensions. The flow properties of filler suspensions in tap water $(\mathrm{pH}=8.3)$ or in lime water $(2 \mathrm{~g} / \mathrm{l}, \mathrm{pH}=12.4)$ were studied at two volumetric solid concentration values (VSC $=0.5$ and $\mathrm{VSC}=0.55$ ). They were defined to assess the jamming effect of particles on rheological properties. Below the 0.50 value, the mixtures were sedimenting and above 0.55 they were too stiff for measurements to be made. The HRWRA (polycarboxylate type) was incorporated in the concentrated filler suspensions (VSC $=0.55$ ) to see whether it acted in the same way with all limestone powders. A concentration of $0.3 \%$ by mass of powder was experimentally defined in order to avoid sedimentation.

3.1.3.1.2. Cementitious suspensions. Cement pastes containing various amounts of each limestone powder were designed by means of the technique of uniform Doelhert networks [25]. Here, three composition

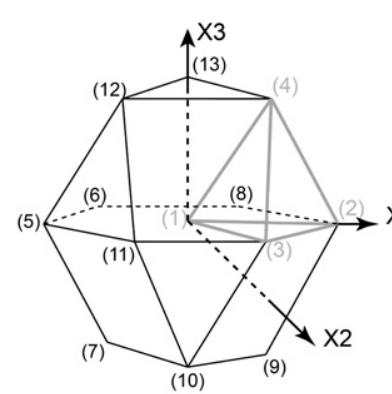

\begin{tabular}{ccccc}
\hline \multicolumn{5}{l}{ Basic simplex (tetrahedron) } \\
\hline $\begin{array}{c}\text { Vertex } \\
\text { coordinates }\end{array}$ & (1) & (2) & (3) & (4) \\
\hline $\mathbf{X}_{1}$ & 0 & 1 & 0.5 & 0.5 \\
$\mathbf{X}_{2}$ & 0 & 0 & 0.866 & 0.289 \\
$\mathbf{X}_{3}$ & 0 & 0 & 0 & 0.816 \\
\hline Domain 1 & beginning & step \\
\hline $\mathbf{P}_{1}$ & 0.20 & 0.10 \\
$\mathbf{P}_{2}$ & 0.30 & 0.05 \\
$\mathbf{P}_{3}$ & 0.01 & 0.002 \\
\hline Domain 2 & beginning & step \\
\hline $\mathbf{P}_{1}$ & 0.25 & 0.10 \\
$\mathbf{P}_{2}$ & 0.26 & 0.05 \\
$\mathbf{P}_{3}$ & 0.01 & 0.002 \\
\hline
\end{tabular}

Fig. 6. Design of cement pastes according to the uniform Doehlert network technique [25].

parameters $\left(P_{1}\right.$ to $\left.P_{3}\right)$ (Fig. 6) were varied, i.e. limestone filler/cement $(\mathrm{LF} / \mathrm{C})$, water/(cement + limestone filler) $(\mathrm{W} /(\mathrm{C}+\mathrm{LF}))$ and HRWRA / (cement + limestone filler) (HRWRA/(C+LF)) ratios by mass. Considering an initial triplet of values $(\mathrm{LF} / \mathrm{C} ; \mathrm{W} /(\mathrm{C}+\mathrm{LF}) ; \mathrm{HRWRA} /(\mathrm{C}+\mathrm{LF})\}$ (point 1 in Fig. 6) and a progression step for each parameter, a meshed experimental domain (cuboctahedron) was generated (Fig. 6) from the basic simplex (tetrahedron in the case of three parameters). Hence, an experimental matrix of 13 paste designs was deduced. For the building of the network, the beginning or centre point (point no. 1, Fig. 6) was experimentally chosen so that the paste was rheologically measurable for all the limestone powders (fluid enough and not sedimenting). Two experimental domains were investigated. The composition of the centred mix and the progression step of each parameter are given in Fig. 6.

3.1.3.2. Mixing sequence. For a given paste, a one-litre batch was prepared using a mixer complying with European Standard EN 196-1 [26]. The entire water amount, along with $1 / 3$ of the HRWRA, was introduced first. The powder was then incorporated for $1 \mathrm{~min}$ at a slow mixing speed. After $30 \mathrm{~s}$ of high speed mixing, a $30 \mathrm{~s}$ rest time was used to manually mix the paste. Then 1 min high speed mixing was applied and the remaining $2 / 3$ of HRWRA was added. Finally, mixing was continued for 2 min at high mixing speed.

3.1.3.3. Flow measurement. For a given mix, three flow properties were measured immediately after the mixing and always with the same timing. First, using the mini-slump test [27], the spreading diameter was measured as the average of two values taken in perpendicular directions at the end of the flow. Then, the paste was rheologically tested with standardized coaxial cylinder geometry (Fig. 7) after 5 min of rest. The diameters of the inner (bob) and outer (cup) cylinders were $\mathrm{Di}=39 \mathrm{~mm}$ and $\mathrm{Do}=42 \mathrm{~mm}$, respectively, providing a gap of $1.5 \mathrm{~mm}$. In order to prevent slipping, the stator and the rotor were sandblasted. The static yield stress and apparent viscosities were
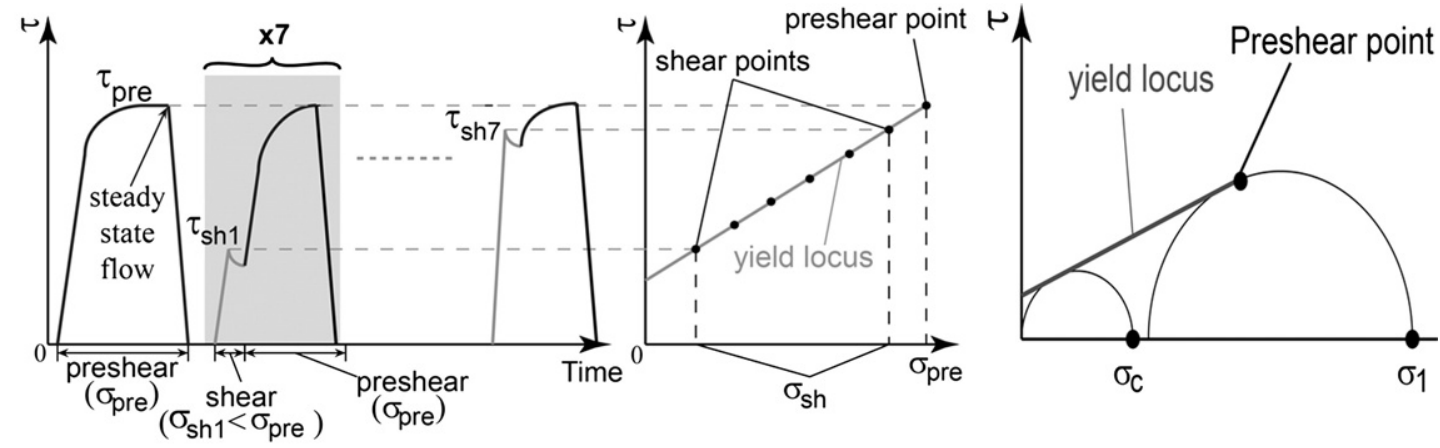

Fig. 5. Shear test procedure for a given consolidation state used to determine the flow function ffc. 

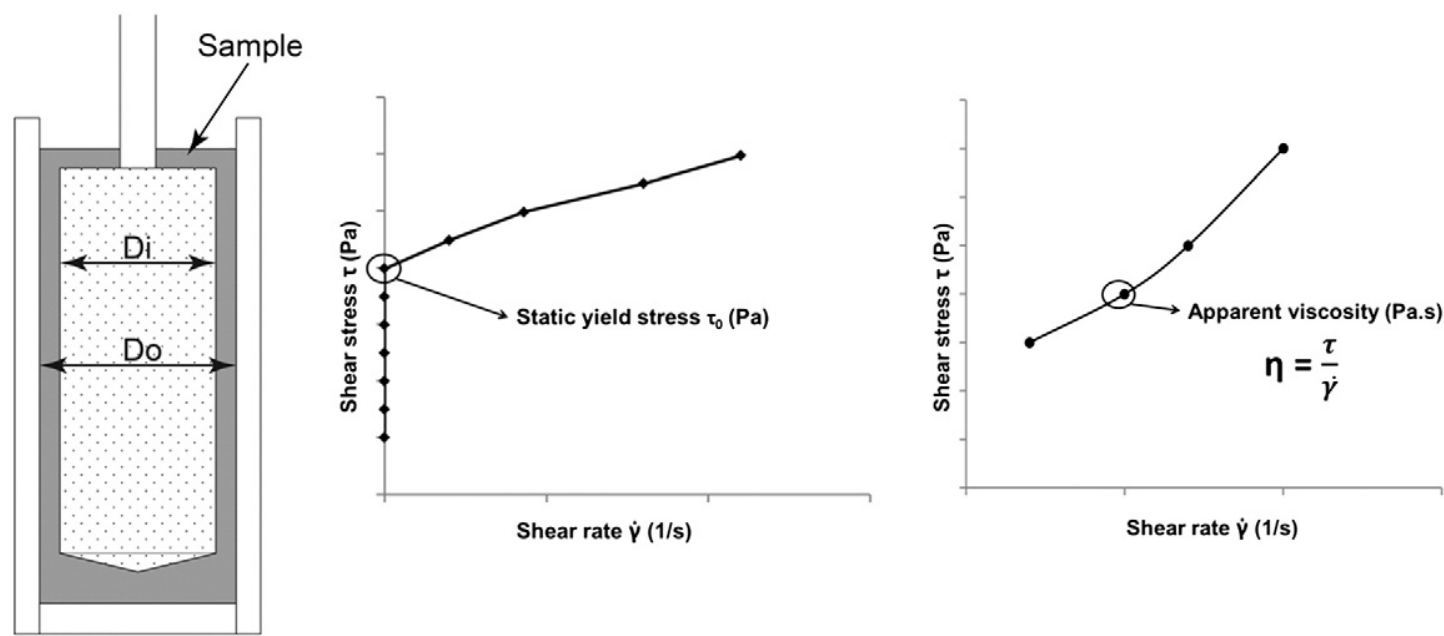

Fig. 7. Shearing geometry (left) and measuring sequences for static yield stress (middle) and apparent viscosities (right).

measured. The temperature was maintained at $20 \pm 0.1^{\circ} \mathrm{C}$ throughout the sequence. The measuring sequence was composed of two steps. In the first part, the controlled stress mode enabled the static yield stress to be determined as the value of the shear stress when the shear rate became different from zero (Fig. 7). In the second part, the viscometer was used in controlled shear rate mode to determine the apparent viscosities. To that end, each paste was first subjected to a rapid increase in shear rate up to $120 \mathrm{~s}^{-1}$ in order to break the structure and overcome the time dependent properties [28]. Second, the shear rate was decreased. For each stage of shear rate (from $100 \mathrm{~s}^{1}$ to $2 \mathrm{~s}^{-1}$ ), the measurement time was maintained long enough (30 s) to achieve a steady state flow and the apparent viscosity was calculated from the average of the last ten shear stress values.

\section{Results}

Before analysing the existence of relationships between i) the flow properties in the different states and ii) the properties of fillers and the flow properties in the various states (Section 5.1), and before defining the most appropriate action to be undertaken to better consider the nature of the filler in view of self-consolidating applications (Section 5.2), the results of the flow properties of powders and powders in suspension are presented in this section.

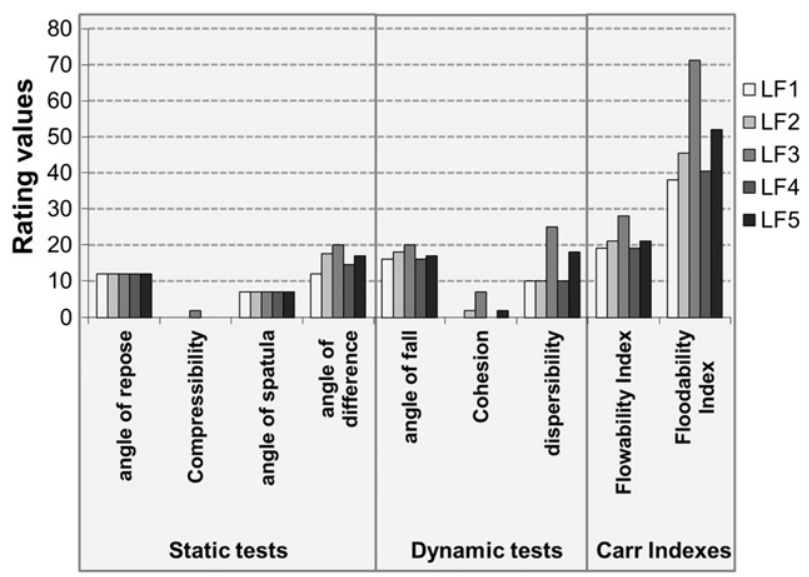

Fig. 8. Flow properties of powders resulting from Carr indexes.

\subsection{Dry powder flow}

\subsubsection{Flowability and floodability}

The rates obtained from the different flow tests and the values of the flowability and floodability indexes are shown in Fig. 8. According to Carr's classification (Table 3), all the fillers showed cohesive behaviour when subjected to static tests. Nevertheless, discrimination was possible thanks to the "dynamic" tests like angle of fall, cohesion and dispersibility, for which the interparticle forces are overcome with exterior energy. Both flowability and floodability index values showed that filler LF3 had the best flow property, followed by (LF5; LF2), and (LF4; LF1).

\subsubsection{Shear under consolidation}

From different consolidation states tested in the ring shear tester (Section 3.1.2), Fig. 9 presents the evolution of the stress, $\sigma c$, necessary to reinitialize the flow versus the major principal stress $\sigma 1$ which consolidated the powder. The position of the flow function ffc in the $\sigma_{1}, \sigma_{\mathrm{c}}$ plane is an objective indicator of the flowability of the powder. Hence, the closer the flow functions are to the $\sigma_{1}$ axis, the less cohesive and more flowable the powder is (Fig. 9). LF1 and LF4 fillers were very cohesive and cohesive under low and high consolidation stresses respectively. Powders LF2 and LF5 were mostly in the cohesive field except for the highest consolidation stress. Only the powder LF3 was classified as easy flowing for all the consolidation states.

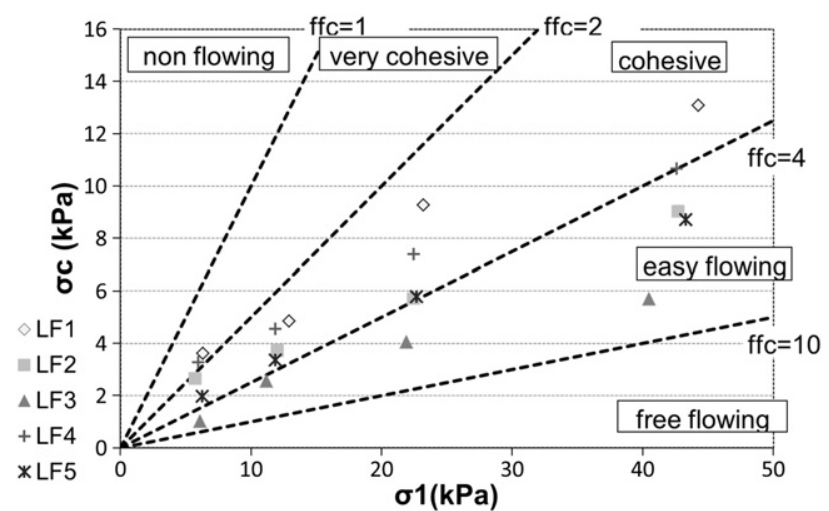

Fig. 9. Flow functions ffc of the five powders determined with the Schulze ring shear cell [24]. 


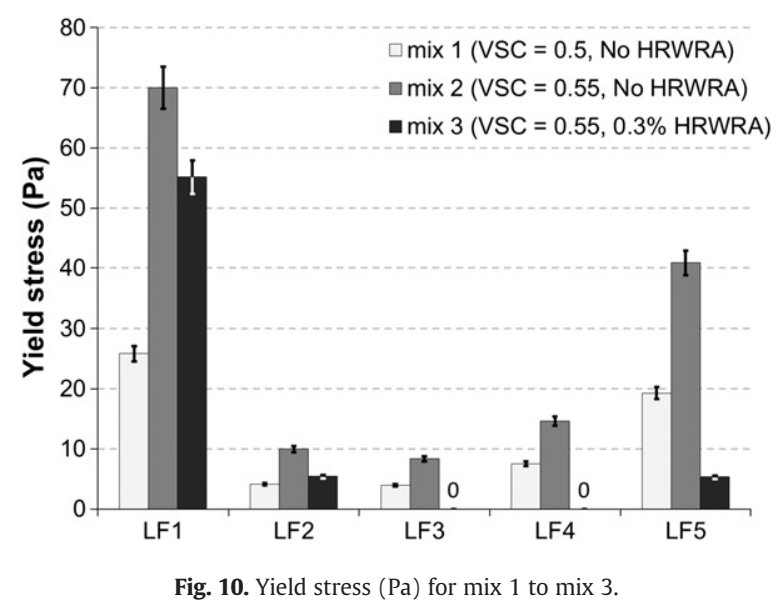

4.2. Rheological testing of limestone suspensions

For the three kinds of mixes tested and made with each limestone powder, the static yield stress and apparent viscosity for a shear rate of $5 \mathrm{~s}^{-1}$ are shown in Figs. 10 and 11 respectively. The evolutions of apparent viscosity values at $5 \mathrm{~s}^{-1}$ according to the nature of the filler are only presented because they are representative of the range of shear rates from $2 \mathrm{~s}^{-1}$ to $30 \mathrm{~s}^{-1}$ in the experimental context. Furthermore, since this range of shear rates is commonly encountered in the placing of concrete [29], apparent viscosities at higher shear rates are not presented.

Also, only the evolutions obtained at a $\mathrm{pH}$ value of 8.5 are shown because they are similar to the ones observed for a $\mathrm{pH}$ value of 12.4 . Both Figs. 10 and 11 deserve some comments.

When no HRWRA was incorporated (mix 1 and mix 2), the following orders were established with regard to tendency to flow.

- Yield stress: LF1 (the highest yield stress) > LF5 > LF4 > LF2 > LF3

(the smallest yield stress).

- Apparent viscosity: LF1 (the highest viscosity) > LF4 > LF2 > LF5 > LF3 (the smallest viscosity).

The use of a HRWRA decreased both the yield stress and the apparent viscosity (comparison between mixes 2 and 3 only) in all cases but in different ways depending on the nature of the limestone filler. The relative decrease in static yield stress was slightly marked for LF1 and LF2 but significant for the others (LF3, LF4 and LF5). Similarly, the apparent viscosities were slightly decreased for LF1, LF2 and LF5 and strongly decreased for LF3 and LF4. These observations are consistent with the measurement of the contact angle (Section 2.2.3). As seen previously, powders LF3, LF4 and LF5 show a lower wettability with superplasticized water (increase in the contact

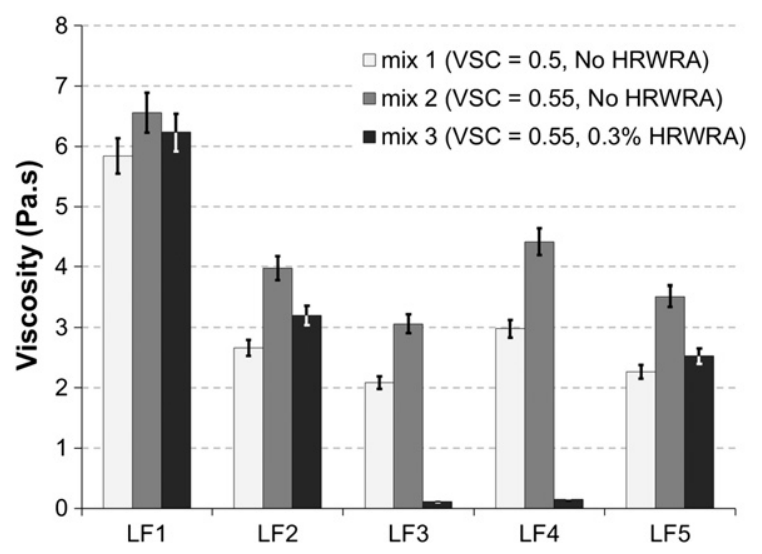

Fig. 11. Apparent viscosities for a shear rate of $5 s^{-1}$ (Pa s) for mix 1 to mix 3.
Table 4

Mix proportion for two cement pastes resulting from Doehlert network.

\begin{tabular}{lllll}
\hline Mix no. & LF/C & W/(C+LF $)$ & HRWRA $/(C+L F)$ & $\begin{array}{l}\text { Volume solid } \\
\text { concentration }\end{array}$ \\
\hline C1 + 25\%LF & 0.25 & 0.26 & 0.01 & 0.557 \\
C1 + 35\%LF & 0.35 & 0.26 & 0.01 & 0.559 \\
C $3+25 \% \mathrm{LF}$ & 0.25 & 0.26 & 0.01 & 0.557 \\
\hline
\end{tabular}

angle). This can explain the larger amount of free water available for the fluidification of the paste when HRWRA is used.

\subsection{Rheological testing of cement pastes}

The previous observations made on the rheological properties of limestone suspensions were no longer valid when cement was added. To illustrate this finding, three mixes resulting from the Doehlert network (Section 3.1.3) were logically selected because they presented the most statistical difference in their rheological properties depending on the nature of the limestone filler (LF) involved. The corresponding design of the mixes is reported in Table 4. The evolution of the corresponding yield stress and viscosity values according to the nature of the LF is plotted in Figs. 12 and 13 respectively. At this stage, we can give some examples demonstrating that the interaction between cement/ HRWRA/limestone filler completely modifies the impact of the nature of the filler on the flow properties of the resulting suspensions. When combined with cement, LF1 filler no longer confers the highest yield stress and viscosity values on the suspension and LF3 filler no longer presents the smallest yield stress and viscosity values (Figs. 12 and 13) depending on the design parameters.

\section{Discussion}

It has been shown that the limestone fillers have very different properties in terms of chemical composition, fineness, size distribution and charge (Section 2) and these properties have a great influence on the flow properties of the powders, both in the dry and suspended states (Section 4). The existence of relationships between the properties of the fillers and flow properties in the different states is now discussed (Section 5.1).

\subsection{Relationships between properties of limestone fillers and their flow} properties in dry and suspended states

All the physical and chemical properties of limestone fillers belonging to the database of the supplier were found not to be normally distributed. Hence non-parametric statistical inference was used to assess the strength of the relationships. First, the analysis of the relationships between the various flow measurements in the

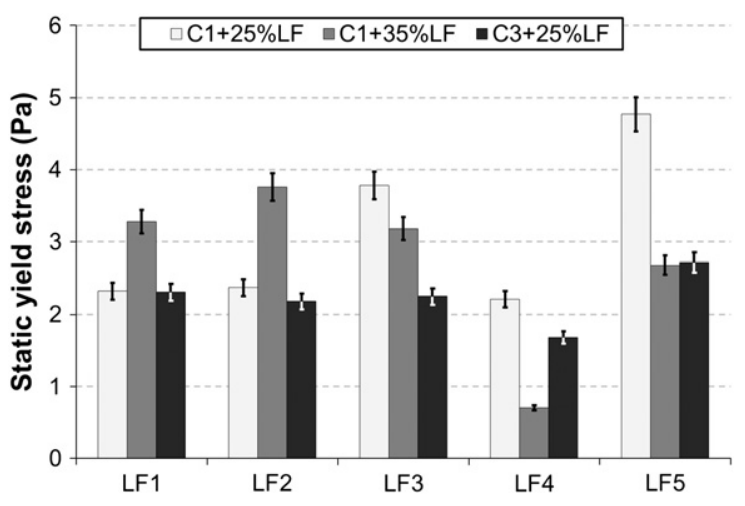

Fig. 12. Static yield stress of cement pastes (Pa). 


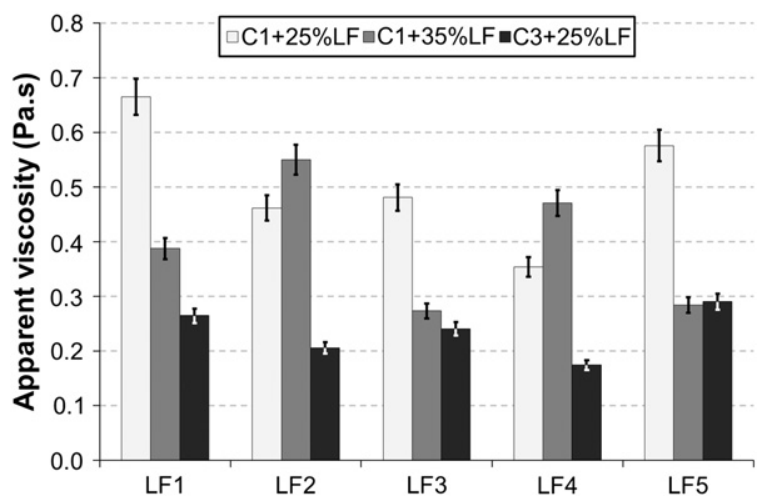

Fig. 13. Apparent viscosity of cement pastes for a shear rate of $5 \mathrm{~s}^{-1}$ (Pa s).

different states studied was based on the Kendall concordance coefficient $W[30]$, (Eq. (1)).

$$
\begin{aligned}
& W=\frac{125}{k^{2}\left(N^{3}-N\right)} \\
& \text { Where } S=\sum_{i=1}^{N}\left(R_{i}-\frac{\sum R_{i}}{N}\right)^{2}
\end{aligned}
$$

$R_{i} \quad$ sum of the ranks for each limestone filler i

$K \quad$ number of flow measurements as ranking criteria ( $k$ varied from 3 to 5 in this study)

$N \quad$ number limestone powders ( $N=5$ in this study).

The hypothesis tested here is that the $k$ rankings are independent. Given a pair of $N$ and $k$ values, if the calculated value of $W$ is higher than the critical value (at the significance level of 0.05 ), then the hypothesis is rejected, i.e. the rankings are not independent. It can be concluded that the fillers are classified in the same order whatever the state of the filler used during the flow measurement (powder or suspension state).

Second, the most relevant properties explaining the flow behaviour of powders, suspended or not, were identified out by using the Kendall rank correlation coefficient $\tau$, which calculates the degree of correspondence between two properties (Eq. (2); Fig. 14).

$\tau=\frac{\sum \text { concordant pairs }-\sum \text { discordant pairs }}{\text { Total number of possible pairs }}$

If $\tau=1(-1)$ then a perfect positive (negative) correlation exists between the two sets of ranks. The Kendall coefficient was chosen because it is insensitive to a value out of the scatter plot. In our case, considering five results (one for each type of filler), and a significance level of 0.05 , the correlations are significant for $\tau>0.80(\tau<-0.80)$.
Table 5

Ranking of dry limestone powder flow and Kendall's coefficient of concordance W.

\begin{tabular}{llllll}
\hline & LF1 & LF2 & LF3 & LF4 & LF5 \\
\hline Flowability & 5 & 2 & 1 & 4 & 3 \\
Floodability & 5 & 3 & 1 & 4 & 2 \\
$f f c$ at $2.5 \mathrm{kPa}$ & 5 & 3 & 1 & 4 & 2 \\
$f f c$ at $19 \mathrm{kPa}$ & 5 & 3 & 1 & 4 & 2 \\
$\mathrm{R}_{\mathrm{i}}$ & 20 & 11 & 4 & 16 & 9 \\
$W=0.963$ and $W>W_{C}$ with $W_{C}=0.553$ for $k=4$ & & &
\end{tabular}

5.1.1. Flow/flow and flow/filler relationships from the dry state to the water suspension

As expected, the five fillers were classified in the same order whatever the flow property measured in the dry state (flowability, floodability) and flow function ffc (measured at $2.5 \mathrm{kPa}$ and $19 \mathrm{kPa}$ consolidation states) (Table 5). The value calculated for the Kendall concordance coefficient $W$ was greater than the critical value $W_{C}$ ( $W=0.963>W_{C}=0.553$ ). The following order was thus validated, from the least to the most cohesive: LF3 $<$ LF5 $<$ LF2 $<$ LF $4<$ LF1.

This order was maintained when powders were suspended in water only $\left(W=1>W_{C}=0.716\right.$, comparing the dry state ranking and the apparent viscosities for the limestone mixes without HRWRA, i.e. mixes 1 and 2, see Fig. $11 ; W=0.87>0.716$ when the dry ranking is compared with the yield stress of the same mixes).

The fineness of the powders qualified by the Blaine specific surface area $S_{S, \text { Blaine }}$ and the percentage of particles under $5 \mu \mathrm{m}$ (\% particle $\left.<5 \mu \mathrm{m}\right)$, was the most influential parameter on the flow in both states, as shown in Table 6. Since $S_{S, \text { Blaine }}$ and \%particle $<5 \mu \mathrm{m}$ properties are also correlated with the surface charges or Zeta potential $(\tau=-0.8)$, it can be concluded that the presence of impurities like clays confers negative charge on the filler and alters the flow. Despite the fact that, without admixtures, the flow of paste can be affected by the shape of the particles [31], it is important to note that no significant relationships were found in this experimental context between the flow in either the powder or the suspension states and the morphology (aspect ratio and form factor) of filler particles in any size classes. The flow was also not correlated with the form (spread or narrow) of the particle size distribution (uniformity coefficient $\mathrm{Cu}$ ). Finally, the perfect negative relationship between the electrostatic charges on particles and their affinity with water measured through the contact angle still showed that the existence of clays decreased the wettability of the LF and degraded the flow. As for the yield stress representing a continued network of interparticle bonding, it was not dominated by the particle charge (Table 6) and the affinity of particles with water. Then, the existence of a yield stress in aqueous filler suspensions is linked to Van der Waals forces rather than electrostatic ones. As a result of attraction between the individual atoms in agglomerated particles, the Van der

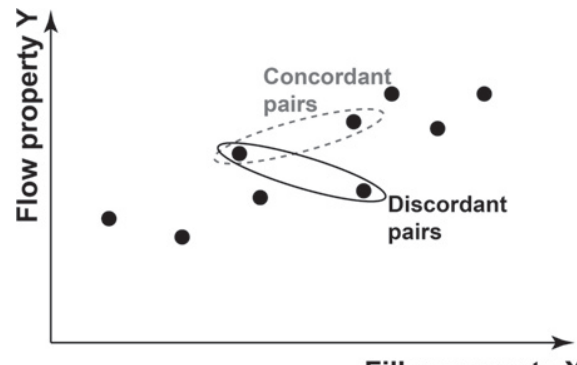

Discordant pair: when $X$ increases, $Y$ decreases

$\tau=\frac{7-3}{10}=0.40$

$\tau<\tau_{\mathrm{c}}\left(\tau_{\mathrm{c}}=0.80\right.$ at 0.05 significance level $)$

Filler property $\mathbf{X} \rightarrow$ no significant correlation

Fig. 14. Illustration of concordant pairs and discordant pairs for the calculation of Kendall's $\tau$ coefficient. 
Table 6

Kendall's $\tau$ values between flow properties of filler suspensions without HRWRA and filler properties (critical $\tau$ value $=0.80$ in absolute value).

\begin{tabular}{llll}
\hline Properties & $\mathrm{S}_{\mathrm{S}, \text { Blaine }}$ & $\%<5 \mu \mathrm{m}$ & $\begin{array}{l}\text { Dry charges } \\
\text { or Zeta potential }\end{array}$ \\
\hline Flowability & -0.89 & -0.89 & 0.67 \\
Floodability & -1.00 & -1.00 & 0.80 \\
$f f c 2.5 \mathrm{kPa}$ & -1.00 & -1.00 & 0.80 \\
$f f c 19 \mathrm{kPa}$ & -1.00 & -1.00 & 0.80 \\
Yield VSC $=0.5$ & 0.60 & 0.60 & -0.40 \\
Yield VSC $=0.55$ & 0.60 & 0.60 & -0.40 \\
Viscosity $5 \mathrm{~s}^{-1} \mathrm{VSC}=0.5$ & 1.00 & 1.00 & -0.80 \\
Viscosity $5 \mathrm{~s}^{-1} \mathrm{VSC}=0.55$ & 1.00 & 1.00 & -0.80 \\
\hline
\end{tabular}

Waals forces are stronger when there is an increase in the fineness of the powder. That is why, irrespective of the solid volume concentration, relationships between yield stress and i) particles passing at $5 \mu \mathrm{m}$ ii) Blaine surface area are fairly consistent (Table 6).

\subsubsection{Flow/flow and flow/filler relationships from the water suspension} to the water + HRWRA suspension

Despite limestone fillers being classified in the same order whatever the rheological properties of suspensions, incorporating HRWRA or not $\left(W=0.742>W_{C}=0.716\right.$ for yield stress and $W=0.867>0.716$ for apparent viscosity), the properties of fillers which affect the flow are not the same as the ones evidenced in Section 5.1.1. As a surfactant, the HRWRA acts on the surface properties of powders so that the BET specific surface area $\left(S_{S, B E T}\right)$ becomes more relevant to take account of the effect of chemical admixtures on the flow of suspensions (Table 7). The $S_{S, B E T}$ parameter remains a coherent representation of the real surface of particles and is more dependent on the impurity (clay) content of the powder (BET/charge, $\tau=-0.80$ and BET/MBA $\tau=0.89)$ than the fineness $\left(S_{S, B E T} /\right.$ Blaine $\tau=0.60, S_{S, B E T} / \%$ particle $<5 \mu \mathrm{m}$, $\tau=0.60$ ) and the morphology (no relationships found between $S_{S, B E T}$ and shape indicators in any size classes). Consequently, strong positive correlations are observed between $\mathrm{S}_{\mathrm{S}, \mathrm{BET}}$ and both yield stress $(\tau=0.95)$ and apparent viscosity $(\tau=1)$ of the limestone powder paste with HRWRA. It should also be pointed out that the HRWRA contains carboxylic acid groups which interact with the existing charges on the surface of the powder particles. Hence, fairly good correlations are found between these particle charges and the flow properties (yield stress and viscosity) of suspensions. The electrostatic interparticle forces become more influential on the yield stress in superplasticized suspensions $(\tau=-0.74)$ than simple aqueous ones $(\tau=-0.40$, Table 6).

As already observed in Section 5.1.1, there are no relationships between the flow properties and the morphology of fillers. This result suggests that impurities like clays cannot generally be considered as grains inserted in the particle distribution that influence the aspect ratio of the filler. Rather, clays are phases included in the grains of filler. Hence, under the effect of the grinding process, these phases become apparent on the surface of grains and modify the surface properties that affect the flow. Also, the extent of the particle size distribution has no significant influence on the flow.

Table 7

Kendall's $\tau$ values between flow properties of filler suspensions with superplasticizer and filler properties (critical $\tau$ value $=0.80$ in absolute value).

\begin{tabular}{|c|c|c|c|c|c|}
\hline Properties & $\mathrm{S}_{\mathrm{S} \text {, Blaine }}$ & $\%<5 \mu \mathrm{m}$ & $\mathrm{MBA}^{\mathrm{a}}$ & $\mathrm{S}_{\mathrm{S}, \mathrm{BET}}$ & Dry charges \\
\hline $\begin{array}{l}\text { Yield stress VSC }=0.55,0.3 \% \\
\text { HRWRA }\end{array}$ & 0.53 & 0.53 & 0.94 & 0.95 & -0.74 \\
\hline $\begin{array}{l}\text { Viscosity } 5 \mathrm{~s}^{-1} \text { VSC }=0.55,0.3 \% \\
\text { HRWRA }\end{array}$ & 0.60 & 0.60 & 0.89 & 1.00 & -0.80 \\
\hline
\end{tabular}

${ }^{a}$ Methylene blue adsorption.
Table 8

Kendall's $\tau$ values between flow properties of cement-based suspensions and filler properties (critical $\tau$ value $=0.80$ in absolute value).

\begin{tabular}{|c|c|c|c|c|c|c|}
\hline$\frac{\text { Properties }}{\text { Suspension }}$ & $\mathrm{S}_{\mathrm{S} \text {, Blaine }}$ & $\begin{array}{l}\%< \\
5 \mu \mathrm{m}\end{array}$ & $\mathrm{MBA}^{\mathrm{a}}$ & $\mathrm{S}_{\mathrm{S}, \mathrm{BET}}$ & $\begin{array}{l}\text { Dry } \\
\text { charges }\end{array}$ & $\mathrm{Cu}$ \\
\hline YS C1 + 25\%LF & -0.60 & -0.60 & 0.00 & -0.20 & 0.40 & 0.40 \\
\hline YS C1 + 35\%LF & 0.00 & 0.00 & 0.45 & 0.40 & -0.20 & 0.60 \\
\hline YS C3 + $25 \%$ LF & -0.20 & -0.20 & 0.45 & 0.20 & 0.00 & 0.40 \\
\hline V C1 + 25\%LF & 0.00 & 0.00 & 0.67 & 0.40 & -0.20 & 0.20 \\
\hline V C1 $+35 \%$ LF & 0.40 & 0.40 & 0.22 & 0.40 & -0.60 & 0.20 \\
\hline V C3 $+25 \%$ LF & -0.20 & -0.20 & 0.45 & 0.20 & 0.00 & 0.4 \\
\hline
\end{tabular}

$\mathrm{YS}=$ Yield stress; $\mathrm{V}=$ viscosity; $\mathrm{Cu}=$ uniformity coefficient.

${ }^{a}$ Methylene blue adsorption (clay content, see Table 1).

5.1.3. Flow/flow and flow/filler relationships from the dry state to the cement + water + HRWRA suspension

The correlations identified when studying the limestone fillers in the dry state and in suspension cannot be generalized to blended mixes of cement and filler.

Analysis can show that there are no relationships between the flow properties of filler suspensions incorporating HRWRA and those of cement-based suspensions ( $W=0.363<W_{C}=0.553$ for yield stress and $W=0.388<0.553$ for viscosity). In addition, the limestone fillers are not classified in the same order by the rheological properties measured on the cementitious suspensions ( $W=0.378<$ $W_{C}=0.716$ for yield stress and $W=0.289<0.716$ for viscosity). Accordingly, it can be concluded that the flow of the complete suspension (cement + LF + HRWRA + water) is not just influenced by the properties of the individual components but also by their concentration and the interactions existing between them. That is why no significant correlation is observed between the properties of fillers and the rheological measurements made on the cement-based suspensions (Table 8 ).

The importance of the interactions can be highlighted by focusing on the behaviour of limestone powder LF3. It was shown that LF3 flowed the most easily, both dry (Sections 4.1.1 and 4.1.2) and in aqueous suspension (Section 4.2) states. The change in the behaviour of LF3 was obvious when it was mixed with cement and HRWRA since the resulting pastes did not present the smallest yield stress and viscosity values. Two phenomena are involved in this behaviour. First, this limestone powder has a size distribution (see Fig. 1) close to that of cement, which can induce strong interaction. Moreover, being strongly positively charged, LF3 powder mobilizes a great part of the HRWRA, composed of carboxylic acid groups. Thus, the HRWRA is no longer available for the dispersion of the cement as the major constituent, and flow alteration becomes visible.

Therefore, at this stage, the lack of relationships between the properties of the fillers and the rheological properties of the cement-based pastes is due to the dilution of the filler in the suspension

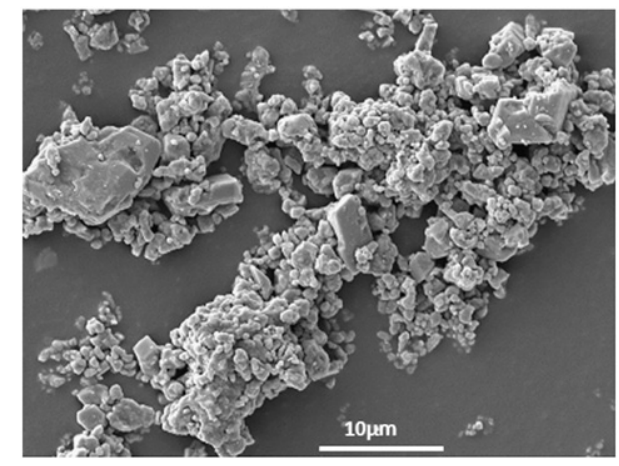

Fig. 15. Agglomerated particles of powder LF1-SEI mode. 
and the strong influence of the interactions existing between the constituents. It is now necessary to define how the properties of filler and cement, and also the resulting interactions, can be taken into account with a view to self-consolidating applications.

5.2. Taking account of particle properties and the interactions between all the components of the suspension

Section 5.1 has clearly shown that the interactions between limestone fillers and the other constituents become dominant in the flow of the suspension when it becomes more and more complex. Some properties of fillers - and undoubtedly of cement - governing these interactions have been identified, such as surface charges, specific surface area and, to a lesser extent, particle size distribution. But, rather than going further on in the understanding of the mechanisms responsible for the interactions, it is now discussed how properties of powders (cement + filler) and resulting interactions with the liquid phase can be united.

\subsubsection{Wet packing density: a relevant parameter}

Due to their small sizes (more than 65\% below $63 \mu \mathrm{m}$ ), grains of filler and cement are dominated by surface forces (Van der Waals and electrostatic forces) and are probably agglomerated in the dry state (Fig. 15).

Accordingly, the flow of filler or cement + filler suspensions will be better related with the characterization of the arrangement of particles in suspension than the measurement of a dry packing density of filler or cement + filler distributions. However, the literature shows that values of the water demand and packing density of cement-based suspensions are largely influenced by the test method employed. The most used test methods are based on a target consistency of the paste, using Vicat apparatus [32], or on the water needed to pass from a humid soil to a thick paste [33], or on the $\beta p$ value (spread measurement of paste with mini-cone [8]). In these methods, the consistencies are arbitrarily fixed and it is assumed that the air content is equal to zero. Here, the wet packing density measurements were achieved following the method proposed by Wong et al. [34,35] because this method does not rely on any consistency observation and automatically takes the air content into account.

\subsubsection{Method for measuring the wet packing density}

The method consists of measuring the apparent density of various pastes at different water/powder ratios $(\mathrm{W} / \mathrm{P})$ by volume. Then, for a given suspension, the void content can be deduced and the void/powder ratio $\mathrm{Rv}$ can be plotted against the $\mathrm{W} / \mathrm{P}$ ratio. The basic water content yielding the minimum void content is then identified (Fig. 16). It should be noted that the minimum void content is composed of water and air entrapped in the structure of the paste.
For a given volume of water $\mathrm{V}_{\mathrm{w}}$ :

1 / Measurement of Mass $M$ of a sample enclosed in a container of known volume $\mathrm{V}$

$2 /$ Calculation of the volume of powder $V_{p}$ (cement + filler) in the sample

$V_{p}=\frac{M}{\rho_{w} R_{w}+\rho_{\alpha} R_{\alpha}+\rho_{\beta} R_{\beta}+\rho_{\gamma} R_{\gamma}}$

where,

$\rho$

cement, filler and active solid of the HRWRA, respectively)

$\mathrm{R}_{\mathrm{w}} \quad$ Water volume $/ \mathrm{V}_{\mathrm{p}}$

$\mathrm{R} \quad$ volumetric ratio of $\alpha, \beta, \gamma$ to the total powder

$3 /$ Calculation of the void ratio

$R_{V}=\frac{V-V_{p}}{V_{p}}$

And the wet packing density

$\Gamma=\frac{V_{p}}{V}=\frac{1}{1+R_{V}}$

For all limestone fillers, the wet packing densities were measured on three cement-based compositions derived from the Doehlert method (Section 3.1.3). The nature of the cement and the $\mathrm{LF} / \mathrm{C}$ and HRWRA/ $(\mathrm{LF}+\mathrm{C})$ ratios by mass of the compositions have already been defined in Table 4.

The mixing sequence was the same as the one used by Wong et al. [34]. First, all the water was put in the mixing bowl with half the HRWRA and powder. Then, 3 min of slow mixing were applied; then, the rest of the powder and HRWRA was added in four steps, again with 3 min mixing at each step.

\subsubsection{Results}

The maximum wet packing density values deriving from the minimum void ratio $R_{V \min }$ values are shown in Fig. 17. From repeatability tests, a scatter of \pm 0.006 was determined on packing density values. Three points are worth noting as they point out the dependence of the arrangement of grains (cement $+\mathrm{LF}$ ) in suspension on the nature and the proportion of LF powder.

- Regarding suspensions incorporating cement C1 (CEM I type), at $25 \%$ LF content, a significantly higher packing density is achieved for LF4 filler than with the other fillers, whereas, at 35\% LF content, the packing density is the highest for LF1 and the lowest for LF3.

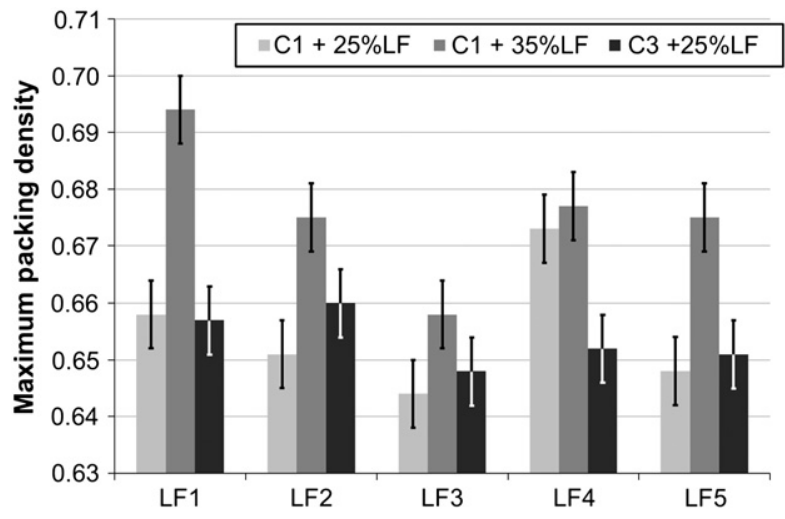

Fig. 17. Maximum packing density of cement pastes.

Fig. 16. Wet packing density test $[34,35]$. 
- As expected, the filler effect is visible when the filler content is increased from $25 \%$ to $35 \%$. This effect (increase in the packing density) is most marked for the powders LF1, LF2 and LF5.

- The change in the nature of the cement (comparison between C1 $+25 \% \mathrm{LF}$ and $\mathrm{C} 3+25 \% \mathrm{LF}$ mixes) can also be evidenced depending on the nature of the filler. When LF4 powder is combined with C3 cement (CEM III type) at a $25 \%$ cement content by mass, there is a significant decrease in the packing density.

Hence, the quantified maximum wet packing density is valuable information and, as such, can be defined as the reference state corresponding to the water demand just necessary to fill the voids between the particles suspended in water + HRWRA. Starting from this reference, the rheological properties of cement-based mixes that incorporate the different limestone fillers at different water volume ratios $R_{w}$ can be studied in relation to the excess water volume ratio defined as: $R_{w}{ }^{\prime}=R_{w}-R_{v}$ min.

The evolutions of static yield stress and apparent viscosity (shear rate value of $5 \mathrm{~s}^{-1}$ ) as a function of the excess water ratio are plotted on Figs. 18 and 19 respectively.

Irrespective of the nature of the cement, and the nature and quantity of the limestone powder, Figs. 18 and 19 clearly show that the flow properties of suspensions become more uniform with increasing excess water ratio. This is a promising result which shows that the rheological properties of fine suspensions can be controlled provided that the interactions between the constituents are taken into account through the characterization of the arrangement of the suspended powder.

In future work, the resulting "rheologically unified" suspensions will be associated with aggregates in order to validate the selfconsolidating ability of concrete with limestone filler of any nature.

\section{Conclusions}

In the aim of identifying the physical and mineralogical properties of limestone filler (LF) which govern the behaviour of these fillers towards self-consolidating flow, a first step, here, was to study the relationships between the flow of LF, from the dry state to the suspension state, and the properties of LF. Then, five LFs were studied, complying with the standards and selected to present significant differences in properties on the basis of the supplier's database. Despite their specific manufacturing, a thorough characterization has shown that the selected LFs have very different properties in terms of surface charges, morphology, wettability and size distribution.

From the results presented in this paper, the following conclusions are drawn.

- Flow properties of dry fillers, such as flowability, floodability and shearing under consolidation, are strongly related to the flow properties (static yield stress and apparent viscosity at $5 \mathrm{~s}^{-1}$ shear rate) of suspensions of fillers in water only. In both states,

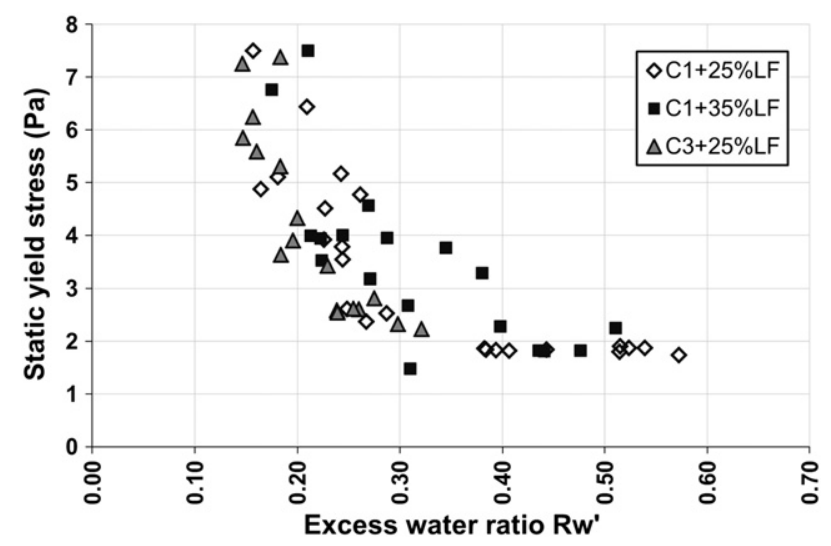

Fig. 18. Static yield stress against excess water ratio.

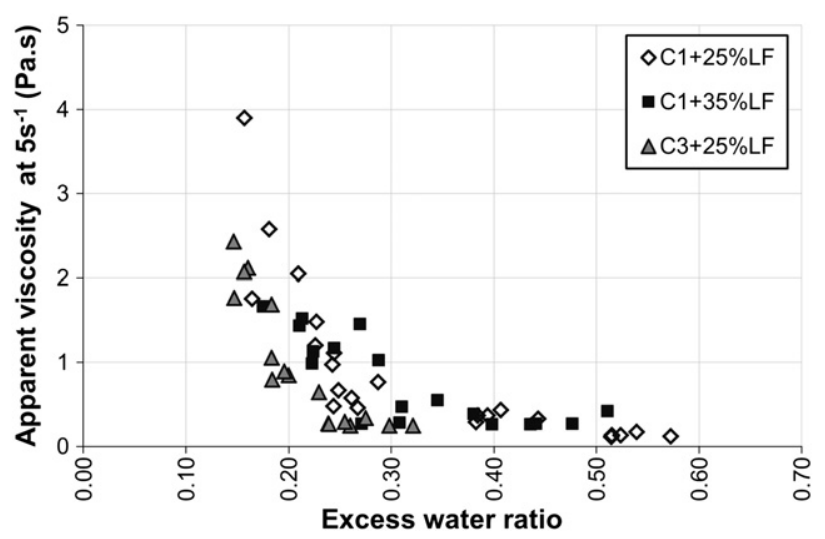

Fig. 19. Apparent viscosities against excess water ratio.

the flow is dependent on the fineness of the powders involved, quantified by the Blaine specific surface area and the percentage of particles under $5 \mu \mathrm{m}$.

- Although the rheological properties of suspensions, incorporating HRWRA (polycarboxylate) or not, classify the LFs in the same order, the $\mathrm{N}_{2}$ BET specific surface area becomes more relevant to take the effect of the High Range Water Reducer Admixture (HRWRA) on the flow of suspensions into account.

- Whether or not HRWRA is incorporated, the significant relationships between the surface charges, wettability and fineness of LFs show that impurities like clays are key factors controlling the flow of LF suspensions. However, the lack of relationship between the flow properties of LF suspensions and the morphology of fillers (aspect ratio and form factor) shows that clays cannot be generally considered as grains inserted in the particle distribution. Rather, clays are phases included in the grains of filler and become apparent on the surface of grains under the effect of the grinding process.

- The result of the methylene blue adsorption test used to qualify the clay content is significantly correlated with the flow of the superplasticized LF suspensions.

- The lack of relationships between i) the flow properties of cement-based suspensions (cement + LF + HRWRA + water) and those of filler, from the dry state to the suspension, and ii) the rheological properties measured on the cementitious suspensions shows that the flow of the complete suspension is not influenced only by the properties of the individual components but also by their concentration and the interactions existing between them. Accordingly, no significant correlation was noted between the properties of LFs and the rheological measurements made on the cement-based suspensions.

- It is possible to identify how best to incorporate LF in a cementbased matrix through the wet packing density test $[34,35]$. The quantified maximum wet packing density is valuable information and can be defined as the reference state corresponding to the water demand just necessary to fill the voids between the particles suspended in water + HRWRA. Starting from this reference, and irrespective of the nature of the cement or the nature and quantity of the limestone powder, the flow properties of suspensions can be uniformized by adjusting the amount of excess water.

The "rheologically unified" suspensions will be associated with aggregates in a forthcoming work, in order to validate the selfconsolidating ability of concrete with any nature of limestone filler.

\section{Acknowledgements}

The authors wish to acknowledge the company CARMEUSE France and the Association Nationale de la Recherche et de la Technologie for their financial support of this research. 


\section{References}

[1] H. Okamura, M. Ouichi, Self-compacting concrete, Journal of Advanced Concrete Technology 1 (2003) 5-15.

[2] P.L. Domone, Self-compacting concrete: an analysis of 11 years of case studies, Cement and Concrete Composites 28 (2006) 197-208.

[3] EN 206-1, Concrete-Part 1: Specification, Performance, Production and Conformity, 2004.

[4] P. Turcry, et al., A study of plastic shrinkage of self-compacting concrete, Proceedings of 3rd International Symposium on Self-Compacting Concrete, August 17-20 2003, Reykjavik, Iceland.

[5] D. Chopin, et al., Creep and shrinkage of heat cured self-compacting concrete, Proceedings of 3rd International Symposium on Self-Compacting Concrete, August 17-20 2003, Reykjavik, Iceland.

[6] V. Boel, et al., Experimental durability evaluation of self-compacting concrete with limestone filler, 4th International Symposium on Self Compacting Concrete, 30 Oct-2 Nov 2005, Chicago, Illinois, 2005.

[7] NF P18-508, Additions pour béton hydraulique-Additions calcaires-Spécifications et critères de conformité, 1995-07-01 (in French).

[8] L. Courard, F. Michel, J. Pierard, Influence of clay in limestone fillers for selfcompacting cement based composites, Construction and Building Materials 25 (2011) 1356-1361.

[9] M. Nehdi, S. Mindess, P.C. Aïtcin, Rheology of high performance concrete: effect of ultrafine particles, Cement and Concrete Research 28 (5) (1998) 687-697.

[10] O. Esping, Effect of limestone filler BET(H2O)-area on the fresh and hardened properties of self-compacting concrete, Cement and Concrete Research 38 (2008) 938-944.

[11] M.R. Jones, L. Zheng, M.D. Newlands, Estimation of the filler content required to minimise voids ratio in concrete, Magazine of Concrete Research 55 (2) (2003) 193-202.

[12] M. Nehdi, Why some carbonate fillers cause rapid increase of viscosity in dispersed cement based materials, Cement and Concrete Research 30 (2000) 1663-1669.

[13] Diederich P., Contribution à l'étude de l'influence des propriétés des fillers calcaires sur le comportement autoplaçant du béton, PhD thesis (in French), 2010.

[14] NF EN 197-1, Cement, part1: composition, specifications and conformity criteria for common cements, 2001

[15] EN 933-9, Tests for geometrical properties of aggregates-Part 9: Assessment of fines-Methylene blue test, 1998.

[16] R. Holtz, W. Kovacs, An Introduction to Geotechnical Engineering, Prentice-Hall, Inc., 1981.

[17] M.L. Hentschel, N.W. Page, Selection of descriptor for particle shape characterization, Particle \& Particle system Characterization 20 (2003) 25-38.
[18] B. Efron, R. Tibshirani, Bootstrap methods for standard errors, confidence intervals, and other measures of statistical accuracy, Statistical Science 1 (1) (1986) 54-77.

[19] J. Plank, B. Sachsenhauser, J. de Reese, Experimental determination of the thermodynamic parameters affecting the adsorption behaviour and dispersion effectiveness of PCE superplasticizers, Cement and Concrete Research 40 (5) (May 2010) 699-709.

[20] M. He, Y. Wang, E. Forssberg, Slurry rheology in wet ultrafine grinding of industrial minerals: a review, Powder Technology 147 (2004) 94-112.

[21] Condotta R., Coulabilité des poudres cohésives: mesures aux faibles contraintes, granulaires humides et application à une poudre industrielle, $\mathrm{PhD}$ thesis (in French), (2005).

[22] Jacquelin M., Etude de la mise en suspension de particules par chute de poudre, $\mathrm{PhD}$ thesis (in French), (2007).

[23] R.L. Carr, Evaluating flow properties of solids, Chemical Engineer 18 (1965) $163-168$.

[24] D. Schulze, Flow Properties of Powders and Bulk Solids, http://www.dietmarschulze.de/grdle1.pdf.

[25] D.H. Doelhert, Uniform shell designs, Journal of the Royal Statistical Society. Series C (Applied statistics) 19 (3) (1970) 231-239.

[26] NF EN 196-1, Methods of Testing Cement-Part 1: Determination of Strength, 2006.

[27] D.L. Kantro, Influence of water-reducing admixtures on properties of cement paste-a miniature slump test, Cement, Concrete and Aggregates 2 (2) (1980) 95-102.

[28] C. Legrand, A contribution to the study of fresh concrete rheology, Materials and Structures 5 (29 \& 30) (1972) 275-295 \& 379-393.

[29] J.S. Reed, Principles of Ceramic Processing; 2nd Edition, John Wiley and Sons, New York, 1996

[30] G. Saporta, Probabilités, analyse des données et statistiques, Editions TECHNIP, 1990 (in French)

[31] A.M.M. Sheinn, D.W.S. Ho, C.T. Tam, Effect of particle shape on paste rheology of SCC, Proceedings of 3rd International Symposium on Self-Compacting Concrete, August 17-20 2003, Reykjavik, Iceland.

[32] NF EN 196-3+A1, Methods of Testing Cement Part 3: Determination of Setting Times and Soundness, 2009.

[33] Sedran T., Rhéologie et rhéométrie des bétons. Application aux bétons autonivellants, PhD thesis (in French), (1999).

[34] H.H.C. Wong, A.K.H. Kwan, Packing density of cementitious materials: part $1-$ measurement using a wet packing method, Materials and Structures 41 (2008) 689-701.

[35] A.K.H. Kwan, H.H.C. Wong, Packing density of cementitious materials: part 2packing and flow of OPC + PFA + CSF, Materials and Structures 41 (2008) 773-784. 